\title{
D. Garritano, Il senso del segreto. Benjamin, Bataille, Deleuze, Blanchot e Derrida sulle tracce di Proust
}

\section{Davide Vago}

\section{(2) OpenEdition}

1 Journals

\section{Edizione digitale}

URL: http://journals.openedition.org/studifrancesi/10585

DOI: $10.4000 /$ studifrancesi. 10585

ISSN: 2421-5856

\section{Editore}

Rosenberg \& Sellier

\section{Edizione cartacea}

Data di pubblicazione: 1 décembre 2017

Paginazione: 580

ISSN: 0039-2944

\section{Notizia bibliografica digitale}

Davide Vago, «D. Garritano, I/ senso del segreto. Benjamin, Bataille, Deleuze, Blanchot e Derrida sulle tracce di Proust», Studi Francesi [Online], 183 (LXI | III) | 2017, online dal 01 février 2018, consultato il 22 janvier 2021. URL: http://journals.openedition.org/studifrancesi/10585 ; DOI: https://doi.org/10.4000/

studifrancesi. 10585

Questo documento è stato generato automaticamente il 21 janvier 2021.

\section{(c)}

Studi Francesi è distribuita con Licenza Creative Commons Attribuzione - Non commerciale - Non opere derivate 4.0 Internazionale. 


\title{
D. Garritano, Il senso del segreto. Benjamin, Bataille, Deleuze, Blanchot e Derrida sulle tracce di Proust
}

\author{
Davide Vago
}

\section{NOTIZIA}

DANIELE GARRITANO, Il senso del segreto. Benjamin, Bataille, Deleuze, Blanchot e Derrida sulle tracce di Proust, Milano/Udine, Mimesis, 2016, «Percorsi di confine/Saggi» 16, XVI+111 pp.

1 Cinque tra le figure maggiori della filosofia novecentesca hanno intessuto un dialogo, talora evidente, talora più sfumato, con l'autore della Recherche. In continuità ideale con il lavoro di A. Simon Trafics de Proust, che abbiamo presentato nella scorsa rassegna, il saggio di Garritano, succinto ma ben calibrato, mette a tema l'aspetto del segreto, con cui l'A. declina un quintuplice dialogo tra le due discipline. Dopo la breve presentazione (pp. VII-XVI) di Bruno MoroncINI, che sottolinea gli intrecci fecondi tra scrittura letteraria e riflessione filosofica, i cinque capitoli del volume sono dedicati ognuno a un pensatore specifico.

2 In «Infanzia e redenzione ovvero Walter Benjamin lettore di Proust» (pp. 7-26), Garritano ricostruisce la rapidità con cui Walter Benjamin, fin dal 1929, si confronta con l'opera proustiana. La tematica del segreto si declina attorno all'essenza del tempo e alla sua reversibilità, un dato cui il filosofo dei Passages si mostra sensibile: la visione proustiana dell'inestricabilità dello spazio-tempo si costruisce nell'infanzia, in cui la lettura si presenta come gioco o come viaggio alla scoperta del segreto racchiuso negli oggetti quotidiani. Recuperare la filosofia del tempo dalla prospettiva dell'infanzia diventa per Benjamin strumento di redenzione.

Il secondo capitolo (pp. 27-46) è dedicato al poliedrico Georges Bataille, che interroga la Recherche dal punto di vista ermeneutico (la nozione di soggetto e i fondamenti di una filosofia del tempo). In particolare «nella distanza fra l'“afferrare" e l'“incarnare" il 
segreto del tempo, si gioca tutta la partita interpretativa di Bataille» (p. 36); nella riflessione sulla sessualità e sulla profanazione (l'episodio di sadismo di Montjouvain) rimane costante l'affermazione che il segreto resta tale anche nel momento in cui viene comunicato ad altri.

4 Con «Gelosia ed origine del pensiero ovvero Gilles Deleuze lettore di Proust» (pp. 47-64), Garritano rilegge l'analisi semeiotica proposta da Deleuze concentrandosi sulla relazione tra gelosia e conoscenza. Il segreto custodito da Albertine è proprio ciò che spinge il protagonista a trasformare la sua infelice scelta amorosa in desiderio di conoscenza mai soddisfatto. Il «dramma epistemologico» della gelosia, i suoi circoli viziosi trovano dunque una sublimazione nella creazione artistica.

5 Il quarto capitolo (pp. 65-77) indaga il concetto di esperienza letteraria di Blanchot in rapporto a Proust. La scrittura proustiana trova la sua ragion d'essere come esperienza dell'introvabile, poiché la rivelazione artistica porta con sé, necessariamente, una parte di perdita. La Recherche è assimilabile al nodo gordiano poiché la sua scrittura «implica sempre un movimento di alterazione e di perdita» (p. 77).

6 L'ultima parte (pp. 79-100) è dedicata alla figura apparentemente più lontana da Proust: Jacques Derrida. Secondo l'A., quest'ultimo è paradossalmente il più proustiano fra $i$ filosofi analizzati. Il segreto e le sue aporie, il suo esprimersi per vie traverse, sono l'anello di congiunzione tra i due: la scrittura secondo Derrida è una forma di "secrezione" che ospita il segreto senza comunicarlo interamente. Proust non potrebbe non essere d'accordo. 